\title{
Retrospective Cohort Study of Cancer Mortality at the Minsk Leather Tannery
}

\author{
Ilya VEYALKIN ${ }^{1 *}$ and Valentin GEREIN ${ }^{2}$
}

\author{
${ }^{1}$ Chair of Environmental Medicine, International Sakharov Environmental University, 23, Dolgobrodskaya str., \\ 220009, Minsk, Belarus \\ ${ }^{2}$ Department of Paediatric Pathology, Institute of Pathology, Johannes Gutenberg University of Mainz, \\ Langenbeckstrasse 1, 55101 Mainz, Germany
}

Received August 31,2005 and accepted November 24, 2005

\begin{abstract}
The cohort of 768 workers who were actively employed for a minimum of 6 months and died was retrospectively followed from 1 January 1953 to 31 December 2000. There were 328 women and 440 men observed. Proportionate mortality ratios (PMRs) were calculated using the Minskcity population mortality proportions to generate expected numbers. The significant excess of pancreatic cancer $(P M R=366 \% ; 95 \% C I=134-800)$ and melanoma and skin cancer $(P M R=455 \%$; 95\% CI=123-1,164) in women-workers of Dyeing and stuffing workshops was shown. The significantly high mortality from pancreatic cancer among Dyeing and stuffing workshops' female workers hired and discharged between 1958 and 1984 (PMR=1,024\% ; 95\% CI=11-2,109), melanoma and skin cancer (PMR=440\%; 95\% CI=240-2,327) among Dyeing and stuffing workshops female workers who started before 1970, lip and buccal cavity among men who began working within 1974-1978 (PMR=1,071\%; 95\% $\mathrm{CI}=\mathbf{2 2 0}-3,128$ ), cervix and corpus uteri cancer among workers employed before 1960 was found. It should be noted that the significantly high mortality from above noted cancers was indicated for Dyeing and stuffing workshops female workers with seniority more than $10 \mathrm{yr}$. Thus it was shown for pancreatic cancer $(P M R=418 \%$; 95\% $C I=136-975)$, for melanoma and skin cancers $(P M R=497 \%$; 95\% CI=102-1,450), for uterus cancers (PMR $=269 \%$; 95\% CI=130-496).
\end{abstract}

Key words: Minsk tannery workers, Proportionate cancer mortality, Pancreas, Kidney, Buccal cavitypharynx, Corpus and cervix uteri, Melanoma and skin

\section{Introduction}

Historically tannery industry has been very popular in Belarus. Leather production includes many operations with different exposures, which can be harmful for the health of workers and particularly be carcinogenic. There are formaldehyde, chromates and bichromates salts, aniline, benzene-based dyes, different organic solvents (butyl acetate, ethanol, benzene, toluene) sulphuric acid, ammonia, hydrogen sulphide and others. It is necessary to note that the basic strategy of leather production is using mostly hydrophobic substances for optimally deep skin impregnation. However, IARC classified occupational

*To whom correspondence should be addressed. exposures in tannery processes as "not classifiable as to carcinogenicity to humans"1) , but some compounds in tanning process was considered as "probably carcinogenic to humans" (some benzene-based dyes ${ }^{1)}$ ) and "carcinogenic to human" (formaldehyde ${ }^{2}$ ). Moreover, some investigations have demonstrated the mutagenic effect of K-ras oncogenes in leather dust ${ }^{3)}$ and some azo-dyes used in leather dyeing in the Salmonella/microsome test ${ }^{4}$. . There were some cohort and case-control studies on tannery workers, which showed significant associations with bladder ${ }^{5-7)}$, nasopharynx and oral cavity cancers ${ }^{8,9)}$. A few called the pancreatic cancer attributive to tanning processes ${ }^{10,11)}$. But there were no earlier cohort mortality examinations among tannery workers, which did not find any significant excess of deaths from any cancers $^{12,13)}$. Despite many publications on cancer in leather industry in international journals we have failed to find any 
such reports in Belorussian, Russian and the USSR press. In this connection our study to evaluate proportionate cancer mortality among workers of Minsk Tannery was important.

\section{Materials and Methods}

We have conducted the retrospective cohort study of proportionate cancer mortality at Minsk Tannery. All considered employees of the enterprise were dismissed from 1 January $1953^{d}$ till 31 December 1995th and were identified from personnel records of workers taken from the archive of the enterprise. Workers with a minimum of 6 months of employment were included in the study. Causes of death were determined from death certificates of Minsk Civilian Registry Archives and records of Minsk Cancer Registry. Information on general mortality level was obtained from Minsk Civilian Registry Archives, Minsk Cancer Registry, and Minsk City Statistics Department. The registration of cohort members' deaths was started from January 1, 1953, and finished in December 31, 2001. Underlying cause of death was coded according to the Ninth Revision of the International Classification of Disease (ICD-9) ${ }^{14)}$.

Using Microsoft Excel software based on methods developed by Monson ${ }^{15)}$ proportionate mortality ratios (PMRs) indirectly standardized by age and calendar time were calculated by comparing the observed number of deaths to the expected number. The numbers of expected deaths were calculated relying on general population data stratified by gender, age (20-24, 25-29, 80-84, 85-elder yr age groups), and calendar time (1953-56, 1957-61, 1997-2001 yr groups). The $95 \%$ confidence intervals ( $95 \% \mathrm{CI}$ ), based on the Poisson distribution, were obtained with the method described by Breslow and Day ${ }^{16}$. Analyses by job department, time hired and dismissed, the latency from the start of occupation to the death and duration of employment were conducted.

The Minsk Leather Tannery has processed buff, pork, sheep and goat hides for shoe making and dressing manufactures. The exposure kind and level could distinguish three departments. The first were tanning-liming workshops with the initial skin processing such as: soaking, liming, washing, fleshing, cutting, deashing and tanning. It seemed the most harmful production with hard manual labour and corrosive environment: compounds of chromium (sodium bichromate in sulphuric acid), formaldehyde, hydrogen sulphide, sulphuric acid, ammonia, and hydrochloric acid. The second part of leather production was performed in dyeing-stuffing and decorating workshops. There were such operations as dyeing, stuffing, dye fixation, drying, wetting, staking, polishing, dust removing, pressing, lacquering and glossing. Following reagents were utilised there: formaldehyde, aniline and benzene-based dyes, fats (synthetic and natural), acrylic emulsions, petroleum and alizarin oils, waxy emulsions, chromic anhydride, liquid ammonia, acetic and formic acids, organic solvents (butyl acetate, ethanol, acetacetate, toluene, benzene, acetone) and formaldehyde. Administrative employees were considered as persons subjected to minimal exposure.

Ingress of xenobiotics into organism seemed to be done by skin penetration (for liquid substances), air inspiration and swallowing of dust particles. Unfortunately information about exposure level was available only for last ten years and in air only. According to data of The Central Chemical Enterprise Laboratory permanent exceeding of formaldehyde in air (more than $0.5 \mathrm{mg} / \mathrm{m}^{3}$ ) was shown at drying and assorting workplaces. All other substances with any carcinogenic ability (Groups 2 and 3) did not exceed the maximum allowable concentration level. Sudden changes of concentration of Chromium compounds, acetic, formic and sulphuric acids, ammonia and dust occurred while processes of chemicals loading and mixtures preparing. High levels of hydrogen sulphide and ammonia were constantly shown in all workshops. In the history of the enterprise the considerable reconstruction took place in 1988, when all equipment, especially waste disposal, were modernized. Thus processes of tanning since 1988 have been followed in closed tanning drums without entering into work area instead open bath used before. Moreover in 1988 processes of tanning extracts preparing were fully excluded and now finished reagents are utilized. Some benzene-based dyes were changed to less harmful, formaldehyde on formic acid and nitro-lacquer replaced by water-containing one.

\section{Results}

The primary cohort consisted of about 3,500 workers; 768 persons (440 males and 328 females) of whom died by December 31, 2001. It is important to note the different gender distribution of workers in departments. Men almost occupied tinning-liming workshops (77\%), while women mainly occupied dyeing-stuffing and decorating workshops (up to $90 \%$ ).

It was established that main causes of death in the cohort were: cardiovascular diseases (males $46.6 \%$ and females $52.2 \%$ ), malignant neoplasms (males $20.2 \%$ and females $26.2 \%$ ), external and unknown causes (males $21.4 \%$ and females $9.5 \%$ ) and respiratory diseases. No significant increases in PMR of main causes were found (Fig. 1). Mean latencies from the onset of work till the death of all causes and $\mathrm{SE}$ were $26 \pm 0.65 \mathrm{yr}$ in males and $33 \pm 0.7 \mathrm{yr}$ in females.

Altogether in the total cohort 175 deaths of all malignant neoplasms were established ( 89 males and 86 females), which was close to expected numbers ( 99.4 for men, $\mathrm{PMR}=90 \%$, $95 \% \mathrm{CI}=72-110$ and 83.6 for women, $\mathrm{PMR}=103 \%$, $95 \% \mathrm{CI}=3-130)$. Mean latencies from the onset of work till the death from cancer and SE were $25 \pm 1.5 \mathrm{yr}$ in males and 


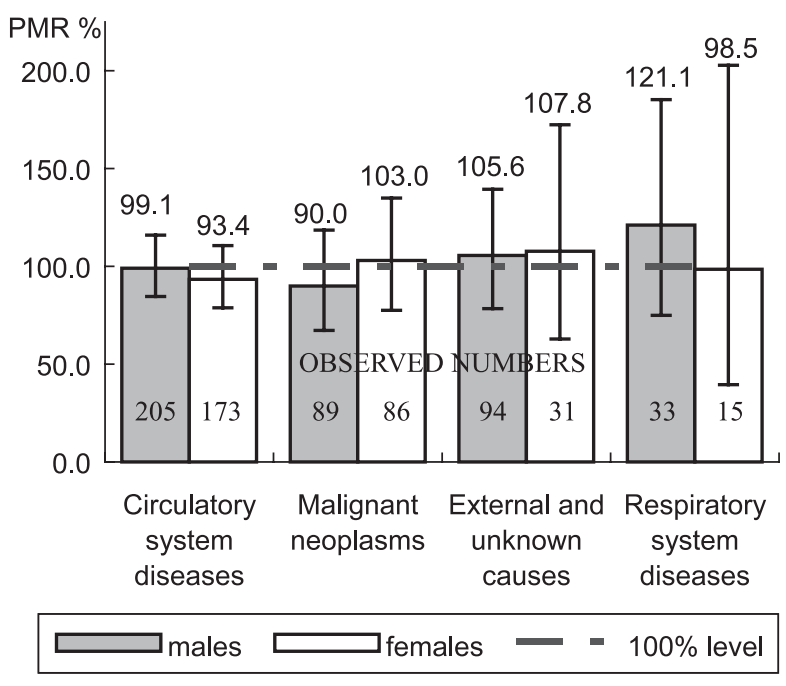

Fig. 1. Observed numbers, PMR, and 95\% CI for Minsk Tannery workers died with main causes.

Table 1. Pancreatic Cancer

\begin{tabular}{|c|c|c|c|c|}
\hline Groups of workers studied & Obs. & Exp. & PMR & $95 \% \mathrm{CI}$ \\
\hline Total cohort $(\mathrm{F})$ & 8 & 2.2 & $363^{*}$ & $156-716$ \\
\hline Total cohort $(\mathrm{M})$ & 5 & 2.6 & 195 & $60-430$ \\
\hline \multicolumn{5}{|c|}{ Dyeing-stuffing and decorating workshops workers $(\mathrm{F})$} \\
\hline & 6 & 1.6 & $366^{*}$ & $134-800$ \\
\hline \multicolumn{5}{|l|}{ Duration of employment } \\
\hline More than 120 months (F) & 5 & 1.19 & $418 *$ & $136-975$ \\
\hline 120-240 months (F) & 5 & 0.6 & $858 *$ & $278-2,000$ \\
\hline \multicolumn{5}{|l|}{ Onset of Employment: } \\
\hline $1958-70(\mathrm{~F})$ & 5 & 0.81 & $613 *$ & $198-1,428$ \\
\hline $1971-80(\mathrm{~F})$ & 2 & 0.15 & $1,283^{*}$ & $155-4,633$ \\
\hline \multicolumn{5}{|l|}{ End of Employment: } \\
\hline $1961-70(\mathrm{~F})$ & 4 & 0.47 & $853 *$ & $232-2,184$ \\
\hline $1971-80(\mathrm{~F})$ & 3 & 0.6 & $499 *$ & $102-1,457$ \\
\hline 1962-66 (F) & 4 & 0.18 & $2,222 *$ & $1,604-5,685$ \\
\hline $1978-84(\mathrm{~F})$ & 4 & 0.25 & $1,600 *$ & $435-4,097$ \\
\hline Occupied within 1958-1984 (F) & 7 & 0.68 & $1,024 *$ & $411-2,109$ \\
\hline
\end{tabular}

Total cohort and groups of female tannery workers with significantly high PMR $\left({ }^{*} \mathrm{p}<0.05 ;\right.$ F-females, M-males $)$.

$30 \pm 1.3 \mathrm{yr}$ in females. Separately we have investigated 13 cancer localizations in males and 17 in females. Pioneering results of cancer mortality in this tannery cohort by departments were presented in previous article ${ }^{17}$. Here we are providing new results of detailed analysis in different groups where interesting result was shown.

\section{Pancreatic cancer (ICD 157)}

The numbers of observed pancreatic cancer deaths, PMR and $95 \% \mathrm{CI}$ for total cohort and groups of tannery workers with significant results are presented in Table 1.
In total cohort significant excess was only shown in females' pancreatic cancer. That was based on eight observed deaths (against 2.2 expected, $\mathrm{PMR}=363 \%, 95 \% \mathrm{CI}=156$ 716). The analysis in details showed that six out of eight pancreatic cancer deaths occurred in women - workers of Dyeing-stuffing and decorating workshops ( $\mathrm{PMR}=366 \%$; 95\% CI $=134-800$ ), one worker was occupied in tanning and liming workshop and one combined both occupations. The significantly high PMR was shown in the group of five workers with the experience more than 120 months ( $\mathrm{PMR}=418 \%$; 95\%CI $=136-975)$ but all those five workers had been occupied for 120-240 months $(\mathrm{PMR}=858$; $95 \%$ CI $=278-2,000)$. By the time of dismissal we could distinguish two quite narrow intervals. Thus four of eight workers were dismissed between 1962 and 66 (PMR $=2,222 \%$; 95\% CI=604-5,689) and four within 1978-84 (PMR=1,600\%; $95 \% \mathrm{CI}=435-4,097)$. It needs to note that all these workers were occupied directly in leather production processes. Four workers were painters, one was a products sorter, two were driers and one was a flesher. Altogether seven female workers were hired since 1958 till 1976 and were dismissed since 1962 till 1984 (PMR=1,024\%; 95\%CI=11-2,109), six of them were occupied in Dyeing-stuffing and decorating workshops $(\mathrm{PMR}=942 \%$; 95\% CI=276-2,053). Also insignificantly high pancreatic cancer PMR was noted in males (five cases, $\mathrm{PMR}=195 \%$; 95\%CI $=60-430$ ). Four of them were occupied in tanning-liming workshops (repairman, quality inspector, flasher and limier) and one in dyeingstuffing workshop (operator of staking machine). But we had no significant results in different compared male groups.

\section{Melanoma and skin cancers (ICD 172-173)}

The significantly high mortality of melanoma and skin cancers was found in female workers occupied in dyeingstuffing and decorating workshops based on four cases $(\mathrm{PMR}=455 \% ; 95 \% \mathrm{CI}=123-1,164)$, all women were employed till 1970 (PMR=440\%; 95\%CI=247-2,327). Three of four had the experience more than 120 months ( $\mathrm{PMR}=497 \%$; 95\% $\mathrm{CI}=102-1,450)$, and two more than 300 months (PMR $=1,279 \%$; 95\%CI=155-4,617) (Table 2). There were three cases of melanoma of skin (ICD 172) and one case of non-melanoma skin cancer (ICD 173).

We also found three cases of skin cancer (head location, ICD 173) in males but no cases of melanoma. Male workers were occupying different places in different departments: one was a foreman in dyeing-stuffing workshop, one was a stableman and one was a repairman in waste refining department. All these workers had the experience more than 72 months (PMR $=833 \%$; 95\% CI=171-2,433). Two of them worked in early fifties.

\section{Corpus and Cervix Uteri (ICD 180, 182)}

Some rise in cervix and corpus uteri mortality were 
Table 2. Melanoma and Skin Cancers

\begin{tabular}{|c|c|c|c|c|}
\hline Studied groups of workers & Obs. & Exp. & PMR & $95 \% \mathrm{CI}$ \\
\hline Total cohort $(\mathrm{F})$ & 4 & 1.26 & 320 & $86-810$ \\
\hline Total cohort $(\mathrm{M})$ & 3 & 1.0 & 300 & $60-810$ \\
\hline \multicolumn{5}{|c|}{ Dyeing-stuffing and decorating workshops workers $(\mathrm{F})$} \\
\hline & 4 & 0.88 & $455^{*}$ & $123-1,164$ \\
\hline \multicolumn{5}{|l|}{ Duration of employment } \\
\hline More then 120 months $(\mathrm{F})$ & 3 & 0.6 & $497 *$ & $102-1,450$ \\
\hline More then 300 months $(\mathrm{F})$ & 2 & 0.15 & $1279 *$ & $155-4,617$ \\
\hline More than 72 months (M) & 3 & 0.36 & $833 *$ & $171-2,433$ \\
\hline \multicolumn{5}{|l|}{ Onset of Employment before } \\
\hline $1970(\mathrm{~F})$ & 4 & 0.91 & $440 *$ & $247-2,327$ \\
\hline
\end{tabular}

Total cohort and groups of tannery workers with significantly high PMR $\left({ }^{*} \mathrm{p}<0.05 ;\right.$ F-females, M-males).

Table 3. Corpus and cervix uteri

\begin{tabular}{|c|c|c|c|c|}
\hline Groups of workers Studied & Obs. & Exp. & PMR & $95 \% \mathrm{CI}$ \\
\hline Total cohort & 12 & 7.5 & 165 & $85-280$ \\
\hline \multicolumn{5}{|l|}{ Duration of employment } \\
\hline More then 120 months & 10 & 3.7 & $269 *$ & $130-496$ \\
\hline $\begin{array}{l}\text { Onset of Employment } \\
\text { before } 1950\end{array}$ & 6 & 2.1 & $290 *$ & $106-633$ \\
\hline $\begin{array}{l}\text { End of Employment } \\
\text { before } 1960\end{array}$ & 7 & 2.1 & $339^{*}$ & $136-700$ \\
\hline
\end{tabular}

Total cohort and groups of tannery workers with significantly high PMR $\left({ }^{*} \mathrm{p}<0.05\right)$.

demonstrated in the total cohort (PMR $=165 \%$; 95\% CI $=85-$ 280), 12 deaths were established. Nine of them were occupied in Dyeing-stuffing and decorating workshops (PMR $=177 \%$; 95\% CI $=80-340$ ); ten had the experience of work more than $10 \mathrm{yr}(\mathrm{PMR}=269 \% ; 95 \% \mathrm{CI}=130-496)$ that was significant. Significant results were also obtained for the workers who had started their operation before 1950 (PMR $=290$; 95\% CI=106-633) and for those who had been dismissed till 1960 (PMR=339 PMR=165\%; 95\% CI=136-700) (Table $3)$.

\section{Buccal cavity, pharynx cancers (140-149)}

In this research we established five cases of buccal cavity and pharynx cancers but no nasal cancers. All cases were noted in men $(\mathrm{PMR}=161 \%$; 95\% CI $=50-370)$, which was non-significant. Significantly high PMR was noted for workers who started their occupation some time in 1974 1978 only ( $\mathrm{PMR}=1071 \%$; 95\% CI=220-3128), there were three cases. All of workers, who had buccal cavity, pharynx cancers, were dismissed till 1986. And all of them were occupied in tanning and liming workshops where exposure of leather dust was not high.
Intestine, Colon and Rectum cancers (ICD 152-154)

Surprisingly we established one case of colon cancer in men against 5.6 expected $(\mathrm{PMR}=17 \%$; 95\% CI $=0.4-97)$. That was significantly low. We could suspect a classification bias if we did not find four cases of colon cancer in females that was quite close to expected 7.2 (PMR $=56 \%$, non significant). Observed numbers of rectum cancer were close to expected both in males (five cases, $\mathrm{PMR}=100 \%$ ) and females (four cases PMR=80\%, non significant). Also there were no cases of intestinal cancers.

\section{Bladder cancer (ICD188)}

Surprisingly we did not find any excess of bladder cancer in whole cohort. Only one case was found in man, who was occupied in tanning-liming workshop.

\section{Discussion}

High mortality of pancreatic cancer in female workers was the main finding of this study. The relatively high mortality of pancreatic cancer in both men and women points to the presence of any common factors, like Chromium compounds. As far as high pancreatic cancer mortality was indicated in females occupied mainly in dyeing-stuffing and decorating workshops, where workers were basically exposed to organic solvents, formaldehyde, aniline and azo-dyes. These chemicals were presented separately in air at some workplaces and were bound with fine leather dust dispersed in air throughout the workshops. Our results could be supported with some others investigations where high pancreatic cancer mortality of tannery workers also was shown ${ }^{10-12)}$. Some investigations demonstrated the mutagenic effect in K-ras oncogenes of leather dust ${ }^{3)}$ and also of 20 azo-dyes used in leather dyeing in the Aims test ${ }^{4}$. Stupar et al. showed the strong ability of proteins of leather dust to bind inorganic chromium III compounds and facilitate their entrance into human in this way ${ }^{18}$. Moreover they reported about ability of chromium compounds to change the tolerance to glucose in older people. This effect was demonstrated in the cohort of tannery workers. Chromium is generally believed to be an essential trace element and to have a role in maintaining proper carbohydrate and lipid metabolism, probably by enhancing insulin signalling ${ }^{19-21)}$. The analysis of publications showed that some occupations with high pancreatic cancer association had similar to tannery exposures. There were pathologists ${ }^{22}$ and laboratory assistants $^{22,23)}$ (high formaldehyde exposure), workers of printing, varnish and painting industry (high exposure of dyes and organic solvents) ${ }^{24)}$. In our research high risk of pancreatic cancer was established for those workers who were occupied within 1958-1984 and especially for those dismissed within 1962-1964 and within 1978-1984. In these years the tannery worked in full operation and used to utilize 
formaldehyde and Direct Black 3 azo-dye. We showed that majority of workers who died with pancreatic cancer were either driers (high formaldehyde exposure) or painters (high dye and solvents exposure). In these conditions we presumed that azo-dyes and/or formaldehyde could initiate DNA mutation and Chromium III promote pancreatic cancer growth. Our earlier observations suggested that many of described above agents could be or inspired either swallowed by workers at the workplaces due to low level of defense of mouth and respiratory tract, which have been noted till present days.

Unfortunately this is a restriction of this study to reconstruct retrospectively the kind of exposure and assess the quantitative level. The history of the enterprise conveyed that tanning and liming operations had not been crucially modified till 1988 whereas Dying-stuffing and decorating operations had been changing during the all time of investigation.

In our study PMRs were calculated separately for men and women so we could not consider gender as risk factor. There were no significant results for pancreatic cancer in men, while they were mainly occupied in tanning-liming workshops. Only $10 \%$ of men were occupied in Dyeingstuffing and decorating workshops and just one of them died with pancreatic cancer that was insufficient for analysis by gender there. In general population pancreatic cancer mortality of females and males are very similar that suggests weak sex influence on this cancer.

It needs to note that strong association between pancreatic cancer and smoking were demonstrated in many studies ${ }^{25-27)}$. Unfortunately it is not known if the cohort had different patterns of alcohol and tobacco consumption than the Minsk general population, but both as cancers of the liver, oesophagus and lung, sites associated with these exposures as deaths with pancreatitis (one case was observed) were not elevated among nor women neither men employees in the tanning plant ${ }^{17}$.

We established the relation between tannery occupation and melanoma of skin or skin cancers. But the analysis of publications showed no reports about association between skin cancers and tannery occupation. One work conducted in the USSR only suggested weak skin carcinogenic effect of some synthetic fats, used under leather stuffing before $1988^{28)}$. As far as majority of cases were established in workers exposed for a long time to leather dyes and fats we could suggest that some leather dyes and mixtures could initiate skin cancer by direct impact. Moreover, some organic solvents, aggressive acid mediums and fat environment could deeply injure the skin. It was important to note that majority of cases were established in workers occupied before 1970 . This fact agrees with above described data on pancreatic cancer.

In some groups of interest we established significantly high PMR of cervix and corpus uteri. Unfortunately we did not manage to study the mortality of cancers cervix cancer and corpus uterus cancer, separately. It was very difficult to get the accurate information from archives of death certificates. In publications we could not find many reports showing the association between cancers of uteri and an occupation in tannery. We could suppose any relations just basing on long occupation of workers died with uteri cancers. We also admitted that high mortality of workers who worked under unfavorable social and economical conditions in the USSR after the World War II and before 1960 could indicate the presence of any confounders.

Many reports associate tannery occupation with oral cavity cancers, particularly with nasal cancers due to leather dust exposure $^{8,9,29,30)}$. We established five cases of buccal cavity and pharynx cancers but no nasal cancers. But significant results were obtained in those who started their occupation in 1974-1978 and were dismissed by 1986 . This could be an evidence of risk factors in the seventyth. But all workers were working in tanning and liming workshops where exposure of leather dust was not high.

The analysis of recent literature data mainly based on casecontrol studies ${ }^{5,6,31,32)}$ showed the prevalence of bladder cancer in the leather industry. But only a few cohort studies ${ }^{7)}$ found the similar significant results. Aromatic amines and benzene-based dyes were suspected as possible carcinogens. In our investigation we observed one case of bladder cancer in man, who was occupied in tanning and liming workshop. We could explain this situation by different gender distribution of workers in workshops mentioned above. Males were mainly occupied in tanning with much lower than females exposition to aniline and benzene-based dyes, which according to many studies are responsible for urothelial cancers. Women, at the same time, had much lower risk to develop bladder cancer than males in general population that was demonstrated by National statistics ${ }^{33)}$. Thus further investigations with larger groups are needed to answer this question.

The present study has several limitations, including the reliance on proportionate mortality data instead of incidence or mortality rates and the lack detailed exposure information. Also, chance cannot be ruled out as possible explanation for study findings, particularly those based on small numbers. Thus further follow-up of this cohort, which would allow more in-depth analysis of rare cancer sites, confounders and adjust for different risk factors, are warranted. Sites of interest include melanoma, pancreas, uterus, nasal, kidney and bladder.

\section{References}

1) International Agency for Research on Cancer (IARC) (1987) IARC monographs on the evaluation of 
carcinogenic risks to humans. Vol 25, Suppl 7. Leather tanning and processing. WHO, Lyon.

2) International Agency for Research on Cancer (IARC) (in preparation) IARC monographs on the evaluation of carcinogenic risks to humans. Vol 88. WHO, Lyon.

3) Saber AT, Nielsen LR, Dictor M, Hagmar L, Mikoczy Z, Wallin H (1998) K-ras mutations in sinonasal adenocarcinomas in patients occupationally exposed to wood or leather dust. Cancer Lett 126, 59-65.

4) Clonfero E, Venier P, Granella M, Levis AG (1990) Leather azo dyes: mutagenic and carcinogenic risks. Med Lav 81, 222-9.

5) Di Menza L, Baron JC, Vieillefond A, Choudat D, BocconGibod L, Zummer K (1992) Risk factors for tumors of the bladder. Epidemiological study of 701 patients in Ilede-France. Presse Med 21, 153-56.

6) Vineis P, Magnani C (1985) Occupation and bladder cancer in males: a case-control study. Int J Cancer 35, 599-606.

7) Montanaro F, Ceppi M, Demers PA, Puntoni R, Bonassi S (1997) Mortality in a cohort of tannery workers. Occup Environ Med 54, 588-91.

8) Comba P, Battista G, Belli S, de Capua B, Merler E, Orsi D, Rodella S, Vindigni C, Axelson O (1992) A case-control study of cancer of the nose and paranasal sinuses and occupational exposures. Am J Ind Med 22, 511-20.

9) Decoufle P (1979) Cancer risks associated with employment in the leather and leather products industry. Arch Environ Health 34, 33-7.

10) Edling C, Kling H, Flodin U, Axelson O (1986) Cancer mortality among leather tanners. Br J Ind Med 43, 4946.

11) Mikoczy Z, Schutz A, Stromberg U, Hagmar L (1996) Cancer incidence and specific occupational exposures in the Swedish leather tanning industry, a cohort based casecontrol study. Occup Environ Med 53, 463-7.

12) Pippard EC, Acheson ED, Winter PD (1985) Mortality of tanners. Br J Ind Med 42, 285-7.

13) Stern FB, Beaumont JJ, Halperin WE, Murthy LI, Hills BW, Fajen JM (1987) Mortality of chrome leather tannery workers and chemical exposures in tanneries. Scand J Work Environ Health 13, 108-17.

14) World Health Organization (WHO) (1992) International classification of diseases, vol. 1, tabular list, ninth revision. WHO, Geneva.

15) Monson RR (1990) Occupational Epidemiology, 2nd ed. CRC Press, Florida.

16) Breslow NE, Day NE (1987) Statistical methods in cancer research: design and analysis of cohort studies. Vol 2. International Agency for Research on Cancer Scientific Publication No. 82. WHO, Lyon.

17) Veyalkin I, Milutin A (2003) Proportionate cancer mortality among workers in the Belorussian tanning industry. Am $\mathrm{J}$ Ind Med 44, 637-42.
18) Stupar J, Vrtovec M, Kocijancic A, Gantar A (1999) Chromium status of tannery workers in relation to metabolic disorders. J Appl Toxicol 19, 437-46.

19) Anderson RA (1998) Chromium, glucose intolerance and diabetes. J Am Coll Nutr 17, 548-55.

20) Anderson RA (1997) Chromium as an Essential Nutrient for Humans. Regul Toxicol Pharmacol 26, 35-41.

21) Bahijri SM, Mufti AM (2002) Beneficial effects of chromium in people with type 2 diabetes, and urinary chromium response to glucose load as a possible indicator of status. Biol Trace Elem Res 85, 97-109.

22) Kernan GJ, Ji BT, Dosemeci M, Silverman DT, Balbus J, Zahm SH (1999) Occupational risk factors for pancreatic cancer: a case-control study based on death certificates from 24 U.S. states. Am J Ind Med 36, 260-70.

23) Rachet B, Partanen T, Kauppinen T, Sasco AJ (2000) Cancer risk in laboratory workers: an emphasis on biological research. Am J Ind Med 38, 651-65.

24) Ji BT, Silverman DT, Dosemeci M, e.a. (1999) Occupation and pancreatic cancer risk in Shanghai, China. Am J Ind Med 35, 76-81.

25) Lin $Y$, Tamakoshi A, Kawamura T, Inaba $Y$, Kikuchi $S$, Motohashi Y, Kurosawa M (2002) A prospective cohort study of cigarette smoking and pancreatic cancer in Japan. Cancer Causes Control 13, 249-54.

26) Lowenfels AB, Maisonneuve P (2002) Epidemiologic and etiologic factors of pancreatic cancer. Hematol Oncol Clin North Am 16, 1-16.

27) Chadirian P, Simard A, Baillargeon J (1991) Tobacco, alcohol and coffee and cancer of the pancreas. Cancer 67, 2264-70.

28) Artamonova L, Saserbekov E (1988) Skin cancer prevention in tannery workers by using fat mixtures. In: Anticancer management. 145-9, Alma-Ata, USSR.

29) Mikoczy Z, Schutz A, Hagmar L (1994) Cancer incidence and mortality among Swedish leather tanners. Occup Environ Med 51, 530-5.

30) Coggon D, Pannett B, Osmond C, Acheson ED (1986) A survey of cancer and occupation in young and middle aged men. I. Cancers of the respiratory tract. Br J Ind Med 43, 332-8.

31) Marrett LD, Hartge P, Meigs JW (1986) Bladder cancer and occupational exposure to leather. Br J Ind Med 43, 96-100.

32) Yamaguchi N, Watanabe S, Okubo T, Takahashi K (1991) Work-related bladder cancer risks in male Japanese workers: estimation of attributable fraction and geographical correlation analysis. Jpn J Cancer Res 82, 624-31.

33) Medical Statistics Department of the Ministry of Public Health of the Republic of Belarus (1998) Public health in the Republic of Belarus, An official statistics collection. Minsk, Belarus. 